\title{
A REGIONAL ANALYSIS OF ESTROGEN BINDING TO HYPOTHALAMIC CELL NUCLEI IN RELATION TO MASCULINIZATION AND DEFEMINIZATION ${ }^{1}$
}

\author{
E. J. NORDEEN AND PAULINE YAHR ${ }^{2}$
}

Department of Psychobiology, University of California, Irvine, California 92717

Received June 23, 1982; Revised November 22, 1982; Accepted December 16, 1982

\begin{abstract}
Gonadal steroids masculinize and defeminize neuroendocrine development, including behavior. Defeminization makes males less sensitive than females to estrogen for showing female sexual behavior and cyclic gonadotropin secretion. Masculinization makes males more sensitive than females to estrogen for showing male sexual behavior. Thus masculinization and defeminization produce opposite effects on estrogen sensitivity. To study the relationship between estrogen sensitivity and estrogen binding, we studied sex differences in estrogen binding to hypothalamic cell nuclei on a regional and temporal basis. We measured the amount of estradiol $\left(\mathrm{E}_{2}\right)$ bound to cell nuclei in the preoptic area (POA), mediobasal hypothalamus (MBH), corticomedial amygdala, and cortex of gonadectomized male and female rats 30 and 60 min after $\left[{ }^{3} \mathrm{H}\right] \mathbf{E}_{2}$ was injected intravenously. In the $\mathrm{MBH}$, males consistently bound less $\mathrm{E}_{2}$ than females did. In the POA, males bound less $\mathrm{E}_{2}$ than females after $60 \mathrm{~min}$, but they bound more $\mathrm{E}_{2}$ than females after $30 \mathrm{~min}$. Decreased estrogen binding in the MBH may underlie defeminized sexual behavior. Similarly, decreased estrogen binding in the POA at 60 min may be a correlate of defeminized gonadotropin secretion, whereas increased estrogen binding in the POA at $30 \mathrm{~min}$ may be a correlate of masculinized sexual behavior. To test the hypothesis that decreased estrogen binding in the MBH and POA are correlates of defeminization, we measured $\mathrm{E}_{2}$ binding at $60 \mathrm{~min}$ in female rats in which masculinization and defeminization were manipulated independently. Defeminization decreased $\mathrm{E}_{\text {? }}$ binding to cell nuclei in both the POA and MBH to the level seen in males at this time point. Masculinization had no effect at this time point. The data suggest that sex differences in $\mathrm{E}_{2}$ binding to hypothalamic cell nuclei correlate reliably with sex differences in estrogen sensitivity even though masculinization and defeminization produce opposing effects on these parameters.
\end{abstract}

At least three reproductive functions involving hypothalamic neurons develop differently in male and female rats-male sexual behavior, female sexual behavior, and gonadotropin secretion. Each involves a sex difference in sensitivity to estrogen. Males are less sensitive than females to estrogen in regard to female sexual behavior. Females show lordosis when mounted if exposed to estradiol $\left(\mathrm{E}_{2}\right)$; males rarely do (Pfaff, 1970; Pfaff and Zigmond, 1971; Whalen et al., 1971). Males are also less sensitive than females to the positive feedback effects of $\mathrm{E}_{2}$ that underlie cyclic secretion of gonadotropins (Neill,

\footnotetext{
${ }^{1}$ This research was submitted by E. J. N. in partial satisfaction of the requirements for the Ph.D. in Biological Sciences. It was supported by National Institute of Mental Health Research Grant MH 26481 to P. Y. We thank Dr. H. C. Kraemer, Department of Psychiatry, Stanford University Medical School, for providing biostatistical advice.

${ }^{2}$ To whom correspondence should be addressed.
}

1972). In contrast, males are more sensitive than females to estrogen in regard to male sexual behavior. $\mathrm{E}_{2}$ is the most important neural metabolite of testosterone $(\mathrm{T})$ for eliciting male sexual behavior (McEwen, 1981) and is more potent for stimulating mount and intromission patterns in males than in females (Pfaff, 1970; Pfaff and Zigmond, 1971).

Lordosis, positive feedback, and mounting are controlled by different populations of hypothalamic neurons, but the sex differences in each of these reproductive functions develop because males are exposed to testicular androgens during a perinatal period of sexual differentiation. When androgens promote development of traits seen in males, e.g., when they increase sensitivity of mounting to $\mathrm{E}_{2}$, they are said to masculinzine development. When they suppress development of traits seen in females, e.g., when they decrease sensitivity of lordosis to $\mathbf{E}_{2}$, they are said to defeminize development (Whalen, 
1974). The inability of males to respond to the positive feedback effect of $E_{2}$ is another example of defeminization.

The bidirectional nature of sex differences in estrogen sensitivity complicates the search for their neural bases. This is particularly true when testing the hypothesis that sensitivity to estrogen depends on the ability of target neurons to bind $\mathrm{E}_{2}$. Reported sex differences in $\mathrm{E}_{2}$ binding in the hypothalamus are unidirectional, favoring females (Whalen and Massicci, 1975; Whalen and Olsen, 1978; Olsen and Whalen, 1980). Thus they provide no correlate for the increased sensitivity of males to $E_{2}$ in regard to mounting behavior. This paradox might be resolved by analyzing $\mathrm{E}_{2}$ binding separately in the mediobasal hypothalamus $(\mathrm{MBH})$ and preoptic area (POA) because these hypothalamic areas are differentially involved in male and female sexual behavior.

The POA mediates hormonal effects on the development and adult expression of mounting (Christensen and Clemens, 1974; Christensen and Gorski, 1978; Davis and Barfield, 1979a; Nordeen and Yahr, 1982). Masculinization may make mounting more sensitive to estrogen by increasing the estrogen-binding ability of POA neurons devoted to this behavior or by increasing their number. Either possibility would lead to males binding more $\mathrm{E}_{2}$ than females in the pertinent POA neurons. However, the POA is also implicated in other effects of estrogen, e.g., induction of maternal behavior (Numan et al., 1977), increased locomotor activity (Wade and Zucker, 1970) and positive feedback control of gonadotropins (Goodman, 1978; Kalra and McCann, 1975; Nance et al., 1977). As noted above, males are less sensitive than females to estrogen in regard to positive feedback. Defeminization may eliminate positive feedback in males by decreasing the estrogen-binding ability of POA neurons subserving this function or by decreasing their number. Either possibility would lead to males binding less $E_{2}$ than females in these POA neurons. Because this hypothesis predicts that the estrogen-binding properties of two POA cell groups are pushed in opposite directions during sexual differentiation, it also predicts that the resulting sex differences in binding will be difficult to detect in POA samples when the cell groups are combined. Any increase in $\mathbf{E}_{2}$ binding related to masculinization of male sexual behavior may be masked by a decrease in $\mathrm{E}_{2}$ binding related to defeminization of gonadotropin secretion. This could explain why previous attempts to detect sex differences in $\mathbf{E}_{2}$ binding in the POA have failed (Maurer and Woolley, 1974; Lieberburg and McEwen, 1977; Lieberburg et al., 1980).

Because the POA cells that control mounting cannot be distinguished from other POA neurons, their $\mathrm{E}_{2}$-binding properties cannot be assayed separately. However, temporal aspects of hormone binding can differ between target tissues sensitive to the same steroid (Keefer, 1981). Thus a temporal analysis of sex differences in $E_{2}$ binding to POA cell nuclei might reveal a time when neurons that control mounting dominate total binding (i.e., males would bind more $\mathrm{E}_{2}$ than females). At other times, neurons that control positive feedback or neurons that mediate estrogen-sensitive processes that are not sexually dimorphic might dominate total binding (i.e., females would bind more $E_{2}$ than males, or no sex differences would appear). Our first experiment explored these possibilities, focusing on earlier time points than those previously studied. We also analyzed temporal aspects of $\mathbf{E}_{2}$ binding in the MBH. The MBH mediates hormonal effects on the development and adult expression of female sexual behavior (Christensen and Gorski, 1978; Davis and Barfield, 1979b; Davis et al., 1979; Nordeen and Yahr, 1982). Like the POA, the MBH is implicated in other effects of estrogen, e.g., negative feedback control of gonadotropins (Bishop et al., 1972) and suppression of food intake (Wade and Zucker, 1970), and it clearly contains a heterogeneous population of estrogen-sensitive cells (Morrell and Pfaff, 1982). However, there is no reason to think that it contains cells that are more sensitive to estrogen in males than in females. Thus $\mathrm{E}_{2}$ binding in the $\mathrm{MBH}$ should never favor males.

After identifying sex differences in $\mathrm{E}_{2}$ binding, we studied their relationship to behavioral differences in estrogen sensitivity. To do this, we chose a time when $\mathbf{E}_{2}$ binding in both the POA and $\mathrm{MBH}$ seemed to be related to defeminization. We then measured $\mathrm{E}_{2}$ binding at this time point in female rats in which masculinization and defeminization were dissociated. This is the first time that $\mathrm{E}_{2}$ binding has been studied in rats whose behavioral sensitivity to estrogen was known.

\section{Materials and Methods}

\section{Regional and temporal analysis of estrogen binding in male and female rats}

Male and female rats (Sprague-Dawley, Simonsen) matched for body weight (mean $\pm \mathrm{SEM}=185 \pm 5 \mathrm{gm}$ for males and $188 \pm 4 \mathrm{gm}$ for females) were gonadectomized under ether anesthesia. Five to 10 days after castration, three to eight animals si each sex were injected via the jugular vein with $40 \mu \mathrm{Cl}$ of $\left[2,4,6,7-{ }^{3} \mathrm{H}(\mathrm{N})\right] \mathrm{E}_{2}$ (New England Nuclear, specific act $19=50$ to $115 \mathrm{Ci} / \mathrm{mmol}$ ) in $0.2 \mathrm{ml}$ of a $25 \%$ ethanol/raline sluiron. Thirty or 60 min later, they were decapitated. ' 1 'htil' brains were removed and kept at $4^{\circ} \mathrm{C}$. Samples of POA, MBH, corticomedial amygdala (AMY), and cortex (CX) were obtained from each brain. The MBH and AMY dissections were the same as those illustrated in Luine et al. (1974). Our POA samples differed from theirs in that we made parallel rather than oblique cuts in the parasagittal plane $1 \mathrm{~mm}$ on either side of the midline. Also, we used only tissue ventral to the anterior commissure. With these dissection boundaries, wet weights in milligrams of tissue samples taken from a separate set of animals $(N=6$ / sex) were: male POA $14.4 \pm 0.5$; female POA $15.8 \pm 1.1$; male MBH $15.4 \pm 0.9$; female MBH $16.6 \pm 1.2$; male AMY $18.1 \pm 0.7$; female AMY $18.9 \pm 1.6$. An analysis of these wet weights revealed no differences between the sexes or between the POA and MBH.

Tissue samples were pooled by region and sex. Purified cell nuclei were isolated from each brain region by a modification of a method outlined by McEwen and Zigmond (1972). Tissues were homogenized and centrifuged at $1000 \times \mathrm{g}$ for $10 \mathrm{~min}$ in NI $(0.32 \mathrm{~m}$ sucrose, $1 \mathrm{mM}$ $\mathrm{KH}_{2} \mathrm{PO}_{4}, 3 \mathrm{mM} \mathrm{MgCl}, 0.25 \%$ Triton; $\mathrm{pH} 6.5$ ). The pellets were resuspended in NII (NI without Triton; $\mathrm{pH} 6.8$ ) and spun again for $10 \mathrm{~min}$ at $1000 \times \mathrm{g}$. The nuclei were then purified by centrifugation at $6900 \times g$ for $2 \mathrm{hr}$ through 
NIII (2.32 $\mathrm{m}$ sucrose, $1 \mathrm{~mm} \mathrm{KH} \mathrm{KH}_{4}, 1 \mathrm{~mm} \mathrm{MgCl}$; $\mathrm{pH}$ 7.0). The nuclear pellets were extracted overnight in $100 \%$ ethanol. The extract was added to $10 \mathrm{ml}$ of scintillation fluor (ACS, Amersham) and counted for radioactivity at approximately $35 \%$ efficiency. Data were expressed as femtomoles of $\mathrm{F}_{22}$ per brain region (e.g., fmol/POA) by dividing the total femtomoles obtained by the number of animals contributing to the nuclear pellet (Kelner et al., 1980). The experiment was repeated five times at each time point.

The DNA content of the nuclear pellets was measured by the Burton (1956) method in 6 of the 10 replications and twice when binding was not assessed. Mean values of micrograms of DNA/region were: male POA $11.85 \pm$ 1.07; female POA $11.33 \pm 0.70$; male MBH $10.58 \pm 1.32$; female MBH $10.99 \pm 1.27$; male AMY $12.55 \pm 0.95$; female AMY 13.54 \pm 1.03 . Again, an analysis of the hypothalamic samples revealed no differences between sexes or regions.

Estrogen binding in the hypothalamus was analyzed by a 2 (time) $\times 2$ (sex) $\times 2$ (region) repeated measures analysis of variance according to the general procedures discussed in Winer (1971) and using a specific design provided by H. C. Kraemer for our experimental protocol. Additional 2 (time) $\times 2$ (sex) analyses of variance were done for each hypothalamic region to locate the source of significant interactions. Estrogen binding in the amygdala was analyzed separately.

\section{Relationship of estrogen binding to masculinization and defeminization}

To better define the relationship between $\mathrm{E}_{2}$ binding and behavioral sensitivity to estrogen, we also measured $\mathrm{E}_{2}$ binding regionally in females that were masculinized but not defeminized, females that were defeminized but not masculinized, females that were both masculinized and defeminized, and females that were neither. We used several approaches to generate these groups, including giving androgen to newborn females systemically, implanting estrogen into the hypothalami of newborn females, and capitalizing on normal variations in sexual behavior, particularly those that depend on exposure to androgen secreted in utero by the female's male sibs (Clemens et al., 1978; Meisel and Ward, 1981).

Neonatal manipulations. Subjects were born to Sprague-Dawley (Simonsen) rats mated in our laboratory. Between 24 and $48 \mathrm{hr}$ after birth, female pups from litters containing fewer males than females received one of the following treatments: bilateral implantation of cholesterol pellets into the POA; bilateral implantation of $\mathrm{E}_{2}$ pellets into the POA; or subcutaneous injection of $500 \mu \mathrm{g}$ of testosterone propionate (TP) in $0.5 \mathrm{ml}$ of safflower oil with or without bilateral implantation of cholesterol pellets in the POA. The steroid pellets were prepared and implanted as described by Christensen and Gorski (1978) except that they were only $0.75 \mathrm{~mm}$ tall. They contained approximately $1 \mu \mathrm{g}$ of steroid each. At least two treatment groups were represented in each litter. Male pups were culled, and females were fostered to maintain litter sizes of six to eight.

Assessment of masculinization/defeminization. Subjects were weaned at 22 days of age and housed in pairs in wire-mesh cages. Throughout the experiment, they were maintained on a $14: 10$-hr light:dark cycle at $23^{\circ} \mathrm{C}$, with food and water freely available. When they were 65 to 80 days old, their ovaries were removed, weighed, and examined under a dissecting microscope for corpora lutea (CL). Females with fewer than two CL/ovary were considered anovulatory.

Starting 2 weeks after ovariectomy, females received daily subcutaneous injections of $2 \mu \mathrm{g}$ of estradiol benzoate (EB) $+200 \mu \mathrm{g}$ of dihydrotestosterone propionate (DHTP) in $0.1 \mathrm{ml}$ of safflower oil for 16 days. They were tested for male sexual behavior on days 7,12 , and 16 of treatment. Starting 2 weeks later, they received $2 \mu \mathrm{g}$ of $\mathrm{EB} /$ day for 12 days and were retested for male sexual behavior on days 7 and 12. For testing male sexual behavior, an experimental female was placed in a clear Plexiglas, cylindrical arena ( 37 to $42 \mathrm{~cm}$ diameter, $51 \mathrm{~cm}$ high) containing sawdust. After $5 \mathrm{~min}$, a sexually receptive stimulus female was introduced. The number of mounts (with thrusting) and intromission patterns that occurred in the next 30 min were recorded. Midway through each test, a new stimulus female was provided unless an intromission pattern had occurred.

One week after the last test for male sexual behavior, subjects received $2 \mu \mathrm{g}$ of $\mathrm{EB} /$ day for 2 days. The next day they received $500 \mu \mathrm{g}$ of progesterone $(\mathrm{P})$ and were tested for female sexual behavior $4 \mathrm{hr}$ later. They then received another 3 days of EB treatment and were retested on the fourth day $4 \mathrm{hr}$ after injection of P. For testing female sexual behavior, subjects were placed into an arena containing a sexually vigorous male (Long Evans). Each test ended after the subject was mounted 10 times. The number of times the subject showed lordosis when mounted was multiplied by 10 to give the lordosis quotient (LQ).

On the basis of the behavioral tests, subjects were classified in terms of both masculinization and defeminization. The defeminized females $[(+)$ def $]$ selected for analysis of $\mathrm{E}_{2}$ binding had low LQ scores (see Figs. 4 and 6) and were anovulatory. Females that were not defeminized [(-)def] obtained high LQ scores; their ovaries were highly vascularized and contained many CL. The masculinized females $[(+)$ masc] selected mounted frequently (see Fig. 4 and 6), whereas only two of the females that were not masculinized $[(-)$ masc $]$ ever mounted a receptive partner. These classifications resulted in four distinct, nonoverlapping behavioral categories: (-) masc/(-)def; (+) masc/(-)def; (-) masc/ $(+)$ def; $(+)$ masc $/(+)$ def. These categories cut across the neonatal hormone treatment groups. The $(+)$ masc/ $(+)$ def females received TP as neonates. Some $(+)$ masc/ $(-)$ def and some $(-)$ masc/(-)def females were exposed to $\mathbf{E}_{2}$ neonatally; others received neither estrogen nor androgen. Females in the $(-)$ masc/ $(+)$ def group were exposed to either $\mathrm{E}_{2}$ or TP neonatally.

Measurement of nuclear binding. At least 3 weeks after the last test for female sexual behavior, groups of three animals from the same behavioral category, and from the same neonatal hormone treatment group, were injected via the jugular vein with $70 \mu \mathrm{Ci}$ of $\left[2,4,6,7-{ }^{3} \mathrm{H}(\mathrm{N})\right] \mathrm{E}_{2}$ (New England Nuclear, 92.4 to $115 \mathrm{Ci}$ / $\mathrm{mmol}$ ) dissolved in $0.2 \mathrm{ml}$ of $25 \%$ ethanol/saline. One hour later, they were decapitated and their brains were removed and placed on ice. Purified nuclear pellets from 
POA, MBH, and CX samples were obtained, and nuclear binding of $\mathrm{E}_{2}$ was assessed as described above. Data were expressed as femtomoles of $\mathrm{E}_{2} /$ region.

In four determinations, $(+)$ masc/(-)def females were compared to $(+)$ masc/ $(+)$ def females. These data were analyzed by a 2 (group) $\times 2$ (region) repeated measures analysis of variance. Four additional determinations compared $(-)$ masc $/(-)$ def females, $(-)$ masc $/(+)$ def females, and $(+)$ masc $/(+)$ def females. Data from this comparison were analyzed by a 3 (group) $\times 2$ (region) design.

\section{Results}

Regional and temporal analysis of estrogen binding in male and female rats. Males and females differed in nuclear $\mathrm{E}_{2}$ binding within the hypothalamus. These sex differences were both regionally and temporally specific as reflected in the significant interactions of sex $\times$ region $\times$ time $(\mathrm{F}(1,8)=12.63, p<0.01)$, sex $\times$ region $(\mathrm{F}(1,8)=$ $7.87, p<0.05)$, and sex $\times$ time $(\mathrm{F}(1,8)=5.91, p<0.05)$. There was no overall effect of sex independent of time and region.

Figure 1 shows the amount of $E_{2}$ in cell nuclei of the MBH 30 and 60 min after $\left[{ }^{3} \mathrm{H}\right] \mathrm{E}_{2}$ injection. Within this region, females bound more $\mathrm{E}_{2}$ than males $(\mathrm{F}(1,8)=$ $10.63, p<0.02$ ). This sex difference did not vary significantly across time.

Nuclear binding of $\mathrm{E}_{2}$ in the POA is illustrated in Figure 2. Here sex differences did change over time ( $F(1$, $8)=10.78, p<0.02)$. Thirty minutes after injection, males bound more $\mathrm{E}_{2}$ than females. Sixty minutes after injection, females bound more $\mathrm{E}_{2}$ than males. In both sexes, binding in the POA was greater than in the $\mathrm{MBH}$ $(\mathrm{F}(1,8)=14.26, p<0.01)$.

To confirm that sex differences in $\mathrm{E}_{2}$ binding were not due to differences in tissue dissection or nuclear yield, we converted $\mathrm{E}_{2}$ binding at $60 \mathrm{~min}$ after injection to femtomoles of $\mathbf{E}_{2} / \mathrm{mg}$ of DNA and reassessed $\mathbf{E}_{2}$ binding in the hypothalamus. Again, females bound more $\mathrm{E}_{2}$ than males $(F(1,3)=52.96, p<0.01)$ and the POA bound more $\mathrm{E}_{2}$ than the $\mathrm{MBH}(\mathrm{F}(1,3)=27.00, p<0.05)$. There was no significant sex $\times$ region interaction at this time point. The mean values expressed as femtomoles of $\mathrm{E}_{2} /$ mg of DNA were: female POA 288.40 \pm 30.18 ; male POA $225.58 \pm 23.01$, female $\mathrm{MBH} 212.15 \pm 25.64$; male $\mathrm{MBH}$ $169.93 \pm 16.74$.

As shown in Figure 3, nuclear binding of $\mathrm{E}_{2}$ in the AMY did not differ between males and females either 30 or 60 min after $E_{2}$ injection. Cortical accumulation of $E_{2}$ was low in all determinations and did not differ between males and females at either time point.

Relationship of estrogen binding to masculinization and defeminization. In the first series of determinations, the effect of defeminization on nuclear $\mathbf{E}_{2}$ binding within the hypothalamus was assessed by comparing $(+)$ masc/ $(-)$ def females to $(+)$ masc $/(+)$ def females. Figure 4 illustrates the behavioral differences between these groups. As shown in Figure 5, females that were both masculinized and defeminized bound less $\mathrm{E}_{2} 60 \mathrm{~min}$ after injection than females that were only masculinized. This decrease is $\mathrm{E}_{2}$ binding in defeminized females only approached statistical significance $(\mathrm{F}(1,3)=6.84, p=0.079)$ when both hypothalamic regions were analyzed together.
Within the POA, $\mathrm{E}_{2}$ binding was significantly reduced $(\mathrm{F}(1,3)=12.45, p<0.05)$.

Cortical binding of $\mathrm{E}_{2}$ was low and did not differ between groups. In these determinations, we detected no difference in $\mathrm{E}_{2}$ binding between the POA and $\mathrm{MBH}$. Mean body weights for $(+)$ masc/(-)def and $(+) \mathrm{masc} /$ (+)def females were $339 \pm 9 \mathrm{gm}$ and $367 \pm 9 \mathrm{gm}$, respectively $(\mathrm{t}(22)=2.97, p<0.01)$.

In the second series of determinations, we compared hypothalamic nuclear $\mathrm{E}_{2}$ binding among (-)masc $/(-)$ def females, $(-)$ masc/ $(+)$ def females, and $(+)$ masc $/(+)$ def females. The behavioral differences among these groups are summarized in Figure 6. The data on $\mathbf{E}_{2}$ binding are shown in Figure 7. As illustrated, the three groups of females differed in nuclear $\mathrm{E}_{2}$ binding $(\mathrm{F}(2,6)=6.01, p$ $<0.05)$. As in the previous determinations, decreased binding was associated with defeminization. The two groups of defeminized females, $(-)$ masc $/(+)$ def and $(+) \mathrm{masc} /(+)$ def, bound less $\mathrm{E}_{2}$ than the $(-) \mathrm{masc} /(-) \mathrm{def}$ females $(\mathrm{F}(1,6)=12.02, p<0.02)$. This decrease was most pronounced in the $\mathrm{MBH}(\mathrm{F}(1,6)=16.02, p<0.01)$, but the POA showed a similar pattern $(\mathrm{F}(1,6)=5.07, p$ $=0.065$ ). Masculinization did not affect nuclear $\mathrm{E}_{2}$ binding in either hypothalamic region as assessed by comparisons between $(-)$ masc/ $(+)$ def females and $(+)$ masc/ $(+)$ def females.

Cortical levels of $\mathrm{E}_{2}$ were always low and did not differ between groups. Again we detected no overall differences in nuclear $\mathrm{F}_{2}$ binding between the POA and MBH. The mean body weights for the three groups of females were: $(-) \mathrm{masc} /(-) \operatorname{def} 356 \pm 13 \mathrm{gm}$; (+)masc/(+) def $390 \pm 15$ $\mathrm{gm} ;(-) \operatorname{masc} /(+) \operatorname{def} 371 \pm 11 \mathrm{gm}(\mathrm{F}(2,23)=1.74, p=$ $0.19)$.

\section{Discussion}

Both the MBH and the POA show sex differences in estrogen binding. Such differences were observed previously for cell nuclei (Whalen and Massicci, 1975; Marrone and Feder, 1977; DeBold, 1978) or chromatin (Whalen and Olsen, 1978; Olsen and Whalen, 1980) isolated from whole hypothalami; however, this is the first time sex differences have been detected in cell nuclei isolated from individual hypothalamic regions.

Sex differences in $\mathrm{E}_{2}$ binding in the $\mathrm{MBH}$ consistently favor females. Because gonadal steroids defeminize female sexual behavior during development (Christensen and Gorski, 1978; Nordeen and Yahr, 1982) and activate lordosis in adults (Davis and Barfield, 1979b; Davis et al., 1979) by acting on the $\mathrm{MBH}$, decreased estrogen binding in the male $\mathrm{MBH}$ may be related, at least in part, to defeminized sexual behavior. This possibility gains support from our observation that females that do not display lordosis show a decrease in $\mathrm{E}_{2}$ binding in the $\mathrm{MBH}$ comparable to the decrease seen in males. This is true when the females' sexual behavior is masculinized and when it is not. Because the behaviorally defeminized females we studied were also defeminized in terms of gonadotropin secretion, their decreased binding of $\mathbf{E}_{2}$ in the $\mathrm{MBH}$ could reflect this function as well: however, the $\mathrm{MBH}$ seems less important than the POA for mediating the positive feedback effects of estrogen (Nance et al., 1977; Goodman, 1978). 


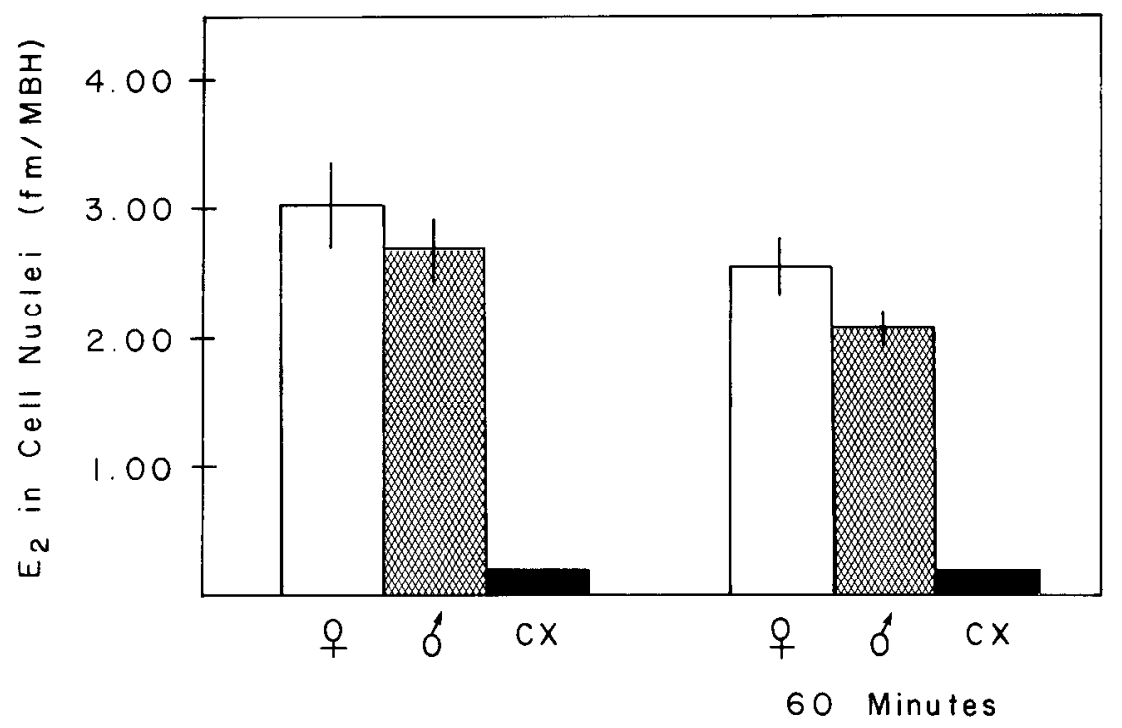

Figure 1. Mean levels of $\mathrm{E}_{2}$ in cell nuclei of the $\mathrm{MBH}$ and $\mathrm{CX}$ of male and female rats 30 and $60 \mathrm{~min}$ after an intravenous injection of $\left[{ }^{3} \mathrm{H}\right] \mathrm{E}_{2}$. Vertical lines denote SEM.

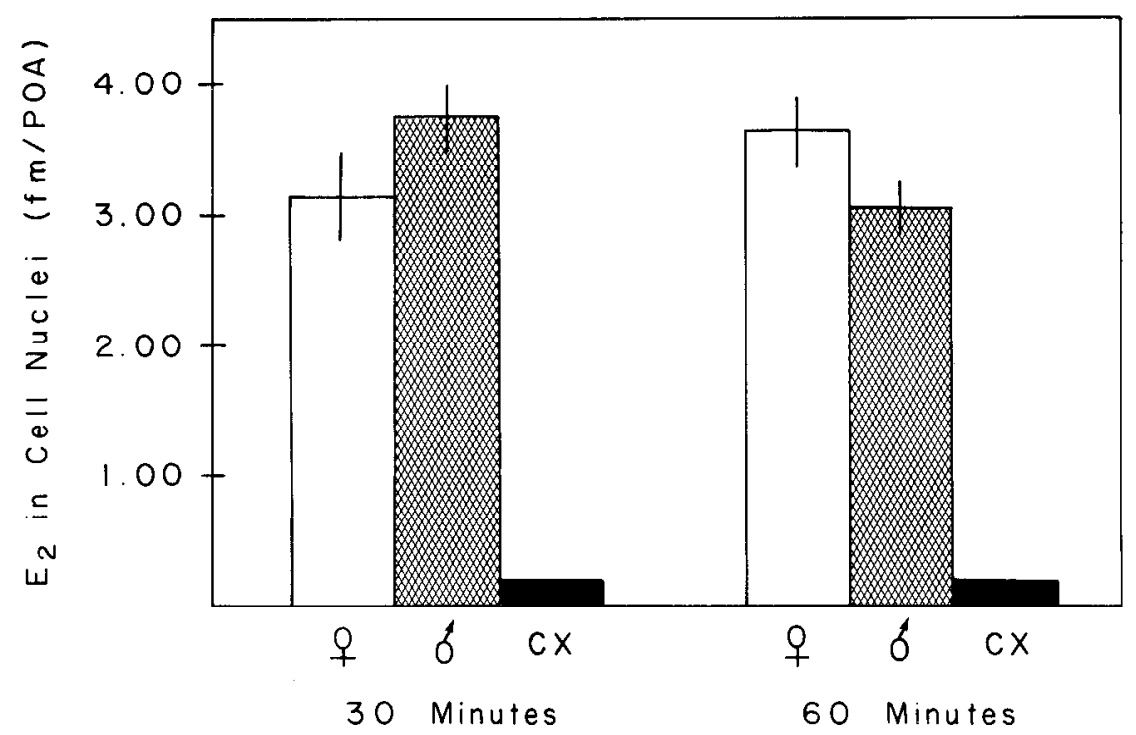

Figure 2. Mean levels ( $\pm \mathrm{SEM}$ ) of $\mathrm{E}_{2}$ in cell nuclei of the POA and CX of male and female rats 30 and 60 min after an intravenous injection of $\left[{ }^{3} \mathrm{H}\right] \mathrm{E}_{2}$.

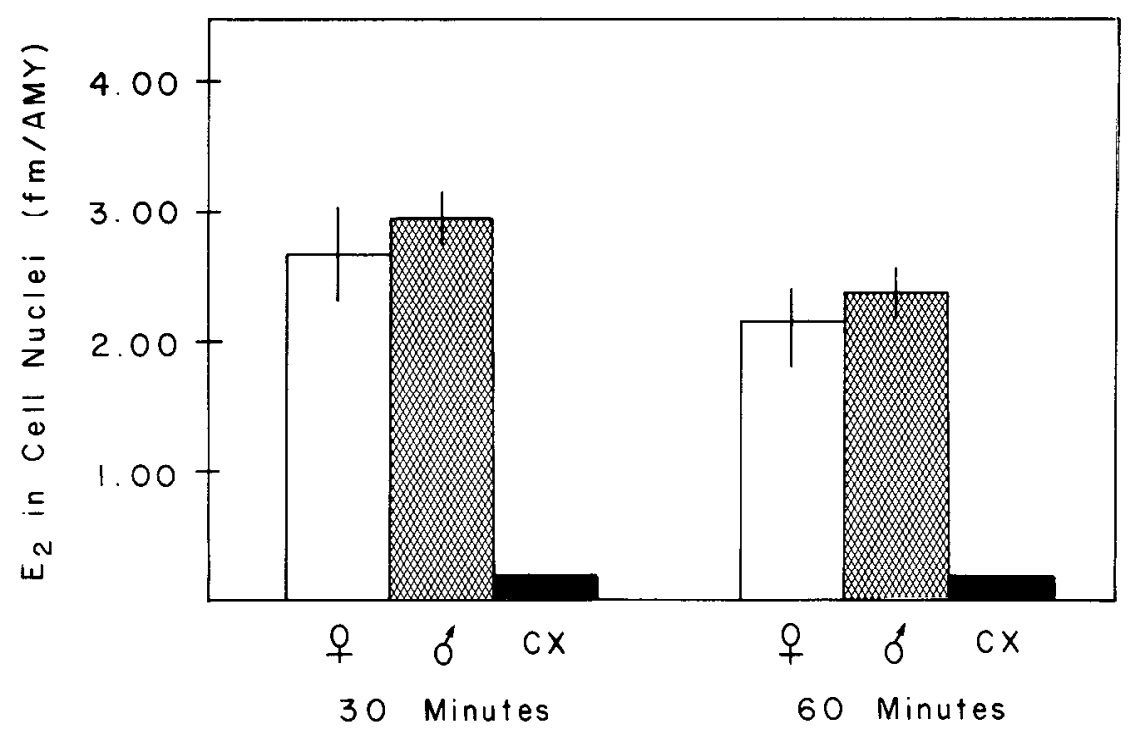

Figure 3. Mean levels ( $\pm \mathrm{SEM}$ ) of $\mathrm{E}_{2}$ in cell nuclei of the AMY and CX of male and female rats 30 and $60 \mathrm{~min}$ after an intravenous injection of $\left[{ }^{3} \mathrm{H}\right] \mathrm{E}_{2}$. 


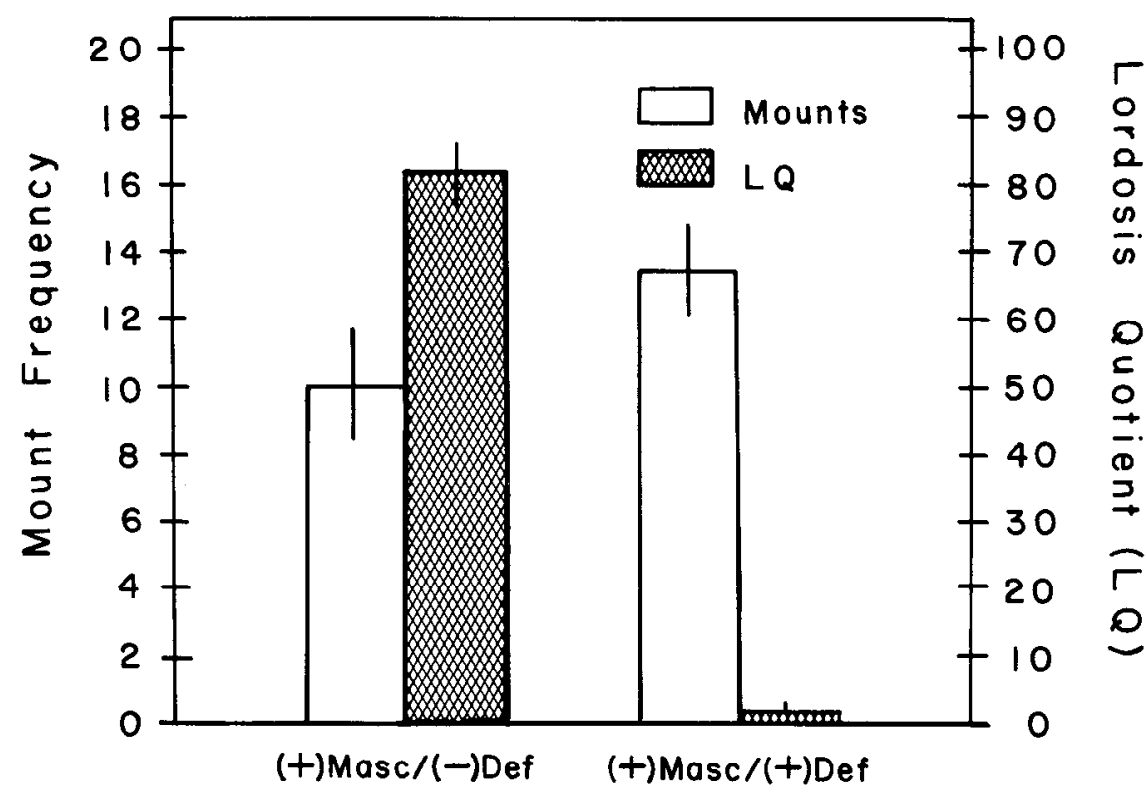

Figure 4. Behavioral profiles of females used to examine the effect of defeminization on nuclear binding of estrogen. Mount frequencies in response to EB + DHTP were averaged over three tests. Lordosis quotients in response to $\mathrm{EB}+\mathrm{P}$ were averaged over two tests. Data shown are the means ( \pm SEM) of these averages. Defeminized females, denoted $(+)$ Def, were also anovulatory. When tested for male sexual behavior while receiving EB alone, defeminized females averaged $7.4 \pm 2.0$ mounts/test. The other group averaged $7.8 \pm 2.5$ mounts/test.

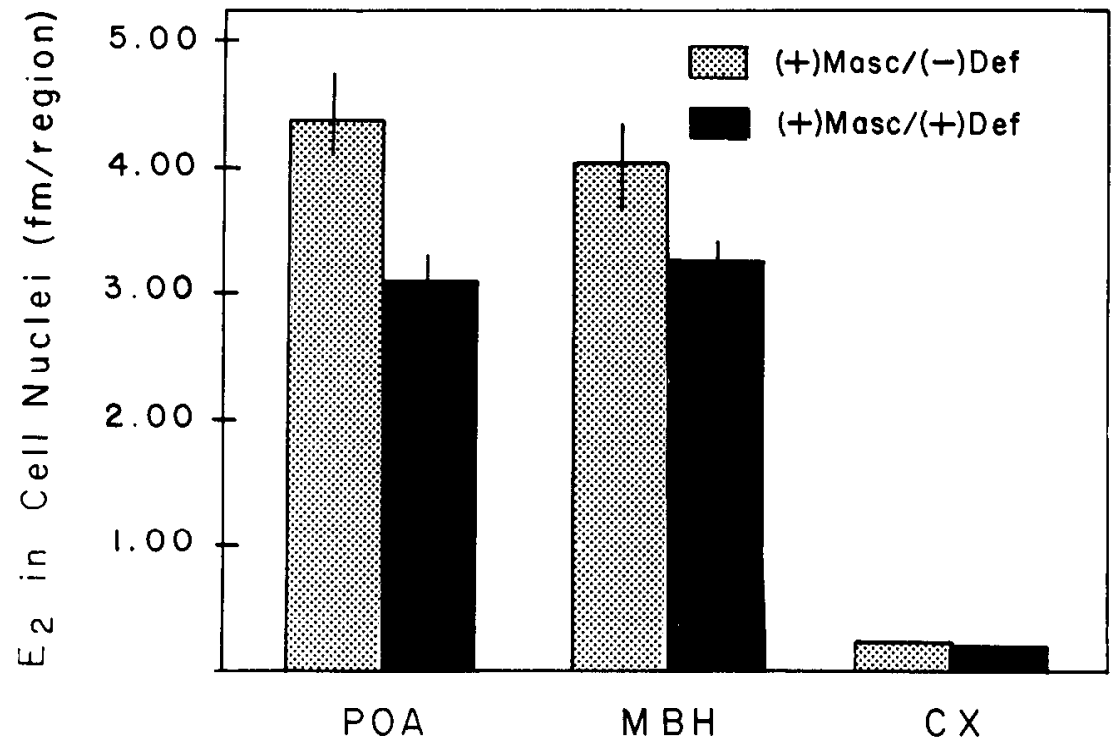

Figure 5. Effect of defeminization on nuclear binding of $\mathrm{E}_{2}$ in the POA and $\mathrm{MBH}$. Data shown are mean levels ( \pm SEM) of $\mathrm{E}_{2}$ in cell nuclei of the POA, $\mathrm{MBH}$, and CX 60 min after an intravenous injection of $\left[{ }^{3} \mathrm{H}\right] \mathrm{E}_{2}$.

Sex differences in $\mathrm{E}_{2}$ binding in the POA can favor either sex depending on the time point analyzed. The POA is implicated in positive feedback control of gonadotropin secretion in adult females (Kalra and McCann, 1975; Nance et al., 1977; Goodman, 1978) and in the development of anovulatory sterility after neonatal hormone treatment (Hayashi, 1976; Nordeen and Yahr, 1982). It also plays a critical role in the development
(Christensen and Gorski, 1978; Nordeen and Yahr, 1982) and adult activation (Christensen and Clemens, 1974; Davis and Barfield, 1979a) of mounting behavior. As noted earlier, the sensitivities of these two reproductive functions to estrogen are forced in opposite directions during sexual differentiation of males. The positive feedback mechanism becomes less sensitive to estrogen. Mounting behavior becomes more sensitive to estrogen. 


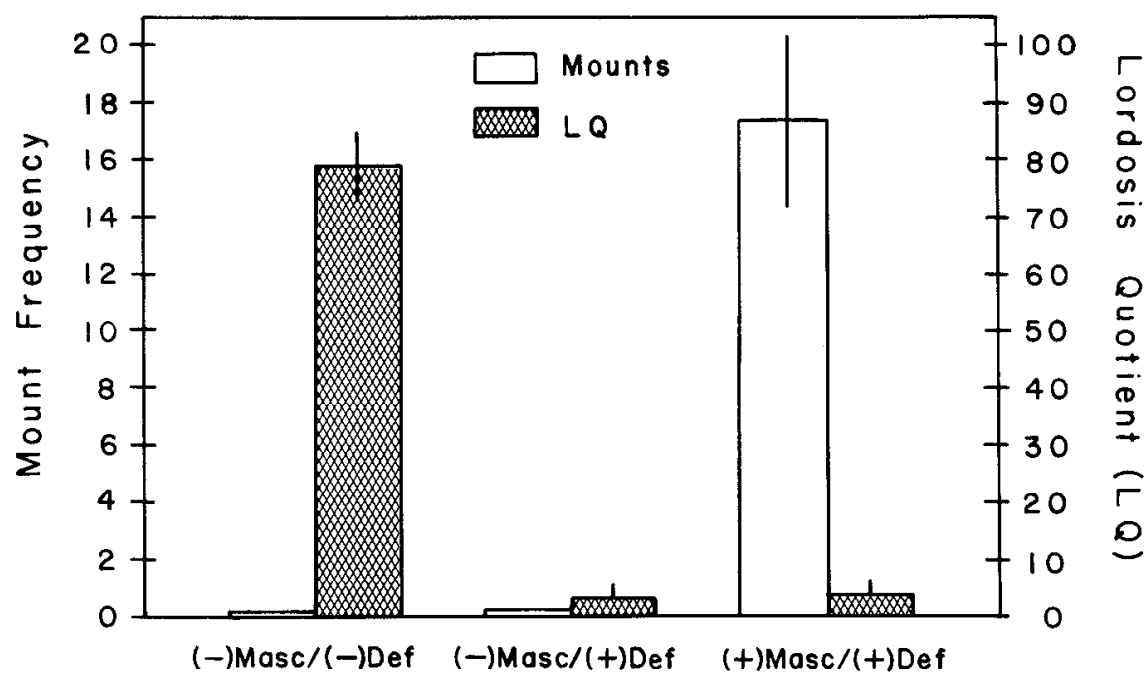

Figure 6. Behavioral profiles of females used to examine the effects of masculinization and defeminization on nuclear binding of estrogen. Data are summarized as described for Figure 4. When tested for male sexual behavior while receiving EB alone, the masculinized females, denoted (+)Masc, averaged $13.5 \pm 3.4$ mounts/test. The other two groups averaged $0.1 \pm 0.1$ and $0.0 \pm 0.0$ mounts/test.

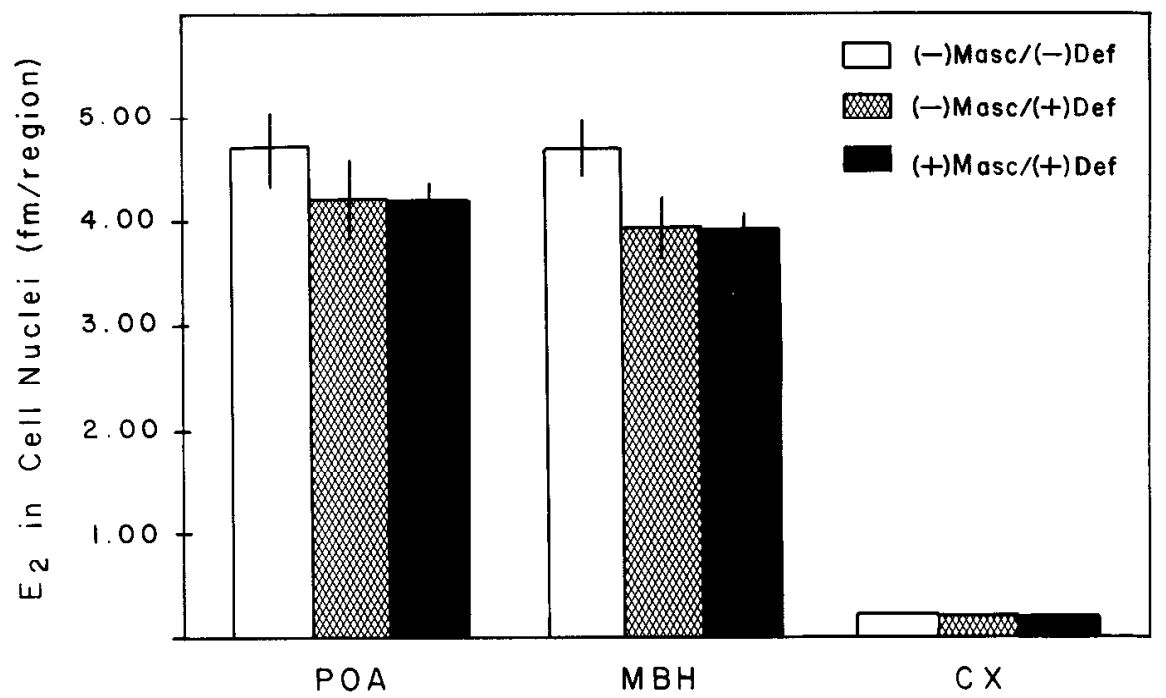

Figure 7. Effect of masculinization and defeminization on nuclear binding of $\mathrm{E}_{2}$ in the POA and MBH. Data shown are mean levels ( $\pm \mathrm{SEM}$ ) of $\mathrm{E}_{2}$ in cell nuclei of the POA, MBH, and CX 60 min after an intravenous injection of $\left[{ }^{3} \mathrm{H}\right] \mathrm{E}_{2}$.

Therefore, we suggest that the sex difference in $\mathrm{E}_{2}$ binding in the POA changes direction over time because it reflects the combined estrogen-binding properties of these two cell groups, and perhaps others like them, and because these cell groups differ in the temporal aspects of their $\mathrm{E}_{2}$ binding.

By this hypothesis, decreased $\mathrm{E}_{2}$ binding in the POA of males $60 \mathrm{~min}$ after injection reflects, at least in part, defeminization of POA neurons mediating positive feedback. This suggestion is supported by the fact that the decrease in $\mathrm{E}_{2}$ binding at this time point in anovulatory females is comparable to the decrease seen in males; behavioral masculinization neither enhances this effect nor alters $\mathrm{E}_{2}$ binding on its own. Because the anovulatory females we studied were also defeminized behaviorally, any contribution of the POA to estrogen control of lordosis could also be reflected in the estrogen-binding properties of this region. The POA inhibits lordosis in female rats (Powers and Valenstein, 1972; Nance et al., 1977; Pfaff and Sakuma, 1979) and estrogen may stimulate lordosis, in part, by suppressing this inhibition (Pfaff, 1980). It is not known, though, if this effect of estrogen is any different in males than in females.

Because some females received steroid-containing implants into the developing POA, it is possible that these POA implants altered the pattern of estrogen binding in this region. If the pellets per se (independent of their steroid content or ncuroendocrine effects) altered $\mathrm{E}_{2}$ binding, they increased it. The groups that bound the most $\mathrm{E}_{2}$, i.e., the females that ovulated and displayed 
lordosis, were the only groups in which all females received steroid (cholesterol or $\mathrm{E}_{2}$ ) pellets neonatally. However, group differences in the presence of pellets did not predict group differences in estrogen binding, because the level of estrogen binding was nearly identical when 3 of 12 females had a POA pellet (females that were both masculinized and defeminized) and when 9 of 12 females had a POA pellet (females that were defeminized but not masculinized; see Fig. 7). On the other hand, early exposure to steroids may have altered estrogen binding slightly even when this was not manifested in the reproductive functions studied here. When females that were defeminized were compared to those that were not (holding masculinization constant), group differences in estrogen binding were smaller when both groups received TP or $\mathrm{E}_{2}$ neonatally (two determinations) than they were in most determinations (five or six) in which only one group received $\mathrm{TP}$ or $\mathrm{E}_{2}$.

Increased estrogen binding in the POA of males $30 \mathrm{~min}$ after injection may reflect, at least in part, masculinization of POA neurons that mediate mounting behavior. Testing this aspect of the hypothesis will require an analysis similar to the one performed here, in which masculinization and defeminization are manipulated independently, and in which estrogen binding is studied 30 min after injection. Nonetheless, the fact that increased $\mathrm{E}_{2}$ binding in males is limited to the POA is consistent with the hypothesis that this sex difference relates to mounting.

The suggestion that POA neurons are heterogeneous in regard to sex differences in estrogen binding gains support from autoradiographic analyses of $\left[{ }^{3} \mathrm{H}\right] \mathrm{E}_{2}$ uptake in the sexually dimorphic nucleus (SDN) and surrounding POA. In rats of both sexes, $\left[{ }^{3} \mathrm{H}\right] \mathrm{E}_{2}$ labels cells in the SDN and in the area lateral to it (Jacobson, 1980). The SDN contains a higher percentage of labeled cells, but, of the two regions, only the lateral one reveals a sex difference in this parameter. Lateral to the SDN, males have a higher percentage of $\mathrm{E}_{2}$-labeled cells than females do. Within the SDN, the percentage of labeled cells is similar in the two sexes, although this implies that males have more labeled SDN cells in total because they have more SDN neurons than females (Gorski et al., 1980). Our POA samples included both of these cell groups, but we cannot specify their contribution to the sex differences we observed. It is unlikely, though, that changes in SDN volume produced the changes in estrogen binding associated with defeminization. The decreases in estrogen binding reported here correlated consistently with behavioral and neuroendocrine defeminization. In contrast, developmental changes in SDN volume after perinatal manipulations of gonadal steroids do not correlate with either of these functions (Gorski et al., 1978).

Regardless of sex or sexual differentiation, all animals accumulate $\mathrm{E}_{2}$ in both the POA and MBH. This is not surprising because these hypothalamic regions mediate still other estrogenic effects besides lordosis, mounting, and ovulation. For some of these effects, estrogen sensitivity is the same in males, females, and androgenized females. The negative feedback effect of estrogen on gonadotropin secretion (Harris and Levine, 1965; Neill, 1972; Mennin and Gorski, 1975) and estrogen-induced increases in locomotor activity (Gentry and Wade, 1976) provide examples. Still other target cell groups must underlie these functions. To activate lordosis behavior in adult female rats, only about $4 \%$ of the nuclear binding sites for $\mathrm{E}_{2}$ in the hypothalamus must be occupied (Davis et al., 1979). This suggests that estrogen's effects on lordosis are mediated by a relatively small proportion of the estrogen-concentrating cells. Thus what seems to be a moderate (15 to 20\%) decrease in $\mathrm{E}_{2}$ binding after defeminization may actually represent a dramatic reduction in $\mathrm{E}_{2}$ binding that is limited to those neurons and/or chromatin acceptor sites that are specifically related to estrogen's effects on lordosis behavior and ovulation. One way in which gonadal hormones present perinatally could reduce or enhance $\mathrm{E}_{2}$ binding is by influencing the survivability of neurons (Arnold, 1981; Jacobson et al., 1980). The death or survival of specific populations of estrogenconcentrating neurons could lead to regionally specific sex differences in $\mathrm{E}_{2}$ binding.

\section{References}

Arnold, A. P. (1981) Model systems for the study of sexual differentiation of the nervous system. Trends Pharmacol. Sci. 2: $148-149$.

Bishop, W., P. S. Kalra, C. P. Fawcett, L. Krulich, and S. M. McCann (1972) The effects of hypothalamic lesions on the release of gonadotropins and prolactin in response to estrogen and progesterone treatment in female rats. Endocrinology 91 : 1404-1410.

Burton, K. (1956) A study of the conditions and mechanism of the diphenylamine reaction of colorimetric estimation of deoxyribonucleic acid. Biochem. J. 62: 315-323.

Christensen, L. W., and L. G. Clemens (1974) Intrahypothalamic implants of testosterone or estradiol and resumption of masculine sexual behavior in long term castrated male rats. Endocrinology 95: 984-990.

Christensen, L. W., and R. A. Gorski (1978) Independent masculinization of neuroendocrine systems by intracerebral implants of testosterone or estradiol in the neonatal female rat. Brain Res. 146: 325-340.

Clemens, L. G., B. A. Gladue, and L. P. Coniglio (1978) Prenatal endogenous androgenic influences on masculine sexual behavior and genital morphology in male and female rats. Horm. Behav. 10: 40-53.

Davis, P. G., and R. J. Barfield (1979a) Activation of masculine sexual behavior by intracranial estradiol benzoate implants in male rats. Neuroendocrinology 28: 217-227.

Davis, P. G., and R. J. Barfield (1979b) Activation of feminine sexual behavior in castrated male rats by intrahypothalamic implants of estradiol benzoate. Neuroendocrinology 28: 228233.

Davis, P. G., B. S. McEwen, and D. W. Pfaff (1979) Localized behavioral effects of tritiated estradiol implants in the ventromedial hypothalamus of female rats. Endocrinology 104: 898-903.

DeBold, J. F. (1978) Modification of nuclear retention of $\left[{ }^{3} \mathrm{H}\right]$ estradiol by cells of the hypothalamus as a function of early hormone experience. Brain Res. 159: 416-420.

Gentry, R. T., and G. N. Wade (1976) Sex differences in sensitivity of food intake, body weight, and running-wheel activity to ovarian steroids in rats. J. Comp. Physiol. Psychol. 90: 747-754.

Goodman, R. L. (1978) The site of the positive feedback action of estradiol in the rat. Endocrinology 102: 151-159.

Gorski, R. A., J. H. Gordon, J. E. Shryne, and A. M. Southam (1978) Evidence for a morphological sex difference within the medial preoptic area of the rat. Brain Res. 148: 333-346.

Gorski, R. A., R. E. Harlan, C. D. Jacobson, J. E. Shryne, and 
A. M. Southam (1980) Evidence for the existence of a sexually dimorphic nucleus in the preoptic area of the rat. J. Comp. Neurol. 193: 529-539.

Harris, G. W., and S. Levine (1965) Sexual differentiation of the brain and its experimental control. J. Physiol. (Lond) 181: $379-400$.

Hayashi, S. (1976) Sterilization of female rats by neonatal placement of estradiol micropellets in anterior hypothalamus. Endocrinol. Jpn. 23: 55-60.

Jacobson, C. D. (1980) The characterization, ontogeny and influence of androgen on the sexually dimorphic nucleus of the preoptic area. Unpublished Ph.D. dissertation, University of California, Los Angeles.

Jacobson, D. C., J. E. Shryne, F. Shapiro, and R. A. Gorski (1980) Ontogeny of the sexually dimorphic nucleus of the preoptic area. J. Comp. Neurol. 193: 541-548.

Kalra, P. S., and S. M. McCann (1975) The stimulatory effect on gonadotropin release of implants of estradiol or progesterone in certain sites in the central nervous system. Neuroendocrinology 19: 289-302.

Keefer, D. A. (1981) Nuclear retention characteristics of $\left[{ }^{3} \mathrm{H}\right]$ estrogen by cells in four estrogen target regions of the rat brain. Brain Res. 229: 224-229.

Kelner, K. L., A. L. Miller, and E. J. Peck, Jr. (1980) Estrogens and the hypothalamus: Nuclear receptor and RNA polymerase activation. J. Recep. Res. 1: 215-237.

Lieberburg, I., and B. S. McEwen (1977) Brain cell nuclear retention of testosterone metabolites, $5 \alpha$-dihydrotestosterone and estradiol-17 $\beta$, in adult male rats. Endocrinology 100: 588597.

Lieberburg, I., N. MacLusky, and B. S. McEwen (1980) Cytoplasmic and nuclear estradiol-17 $\beta$ binding in male and female rat brain: Regional distribution, temporal aspects and metabolism. Brain Res. 193: 487-503.

Luine, V. N., R. I. Khylchevskaya, and B. S. McEwen (1974) Oestrogen effects on brain and pituitary enzyme activities. J. Neurochem. 23: 925-934.

Marrone, B. L., and H. H. Feder (1977) Characteristics of $\left({ }^{3} \mathrm{H}\right)$ estrogen and $\left({ }^{3} \mathrm{H}\right)$ progestin uptake and effects of progesterone on $\left({ }^{3} \mathrm{H}\right)$ esirogen uplake in brain, anterior pituitary and peripheral tissues of male and female guinea pigs. Biol. Reprod. 17: 42-57.

Maurer, R. A., and D. E. Woolley (1974) Demonstration of nuclear ${ }^{3} \mathrm{H}$-estradiol binding in hypothalamus and amygdala of female, androgenized-female and male rats. Neuroendocrinology 16: 137-147.

McEwen, B. S. (1981) Neural gonadal steroid actions. Science 211: 1303-1311.

McEwen, B. S., and R. E. Zigmond (1972) Isolation of brain cell nuclei. In Methods in Neurochemistry, N. Marks and R. Rodnight, eds., pp. 139-161, Plenum Press, New York.

Meisel, R. L., and I. L. Ward (1981) Fetal female rats are masculinized by male littermates located caudally in the uterus. Science 213: 239-242.

Mennin, S. P., and R. A. Gorski (1975) Effects of ovarian steroids on plasma LH in normal and persistent estrous adult female rats. Endocrinology 96: 486-491.

Morrell, J. I., and D. W. Pfaff (1982) Characterization of estrogen-concentrating hypothalamic neurons by their axonal projections. Science 217: 1273-1276.

Nance, D. M., L. W. Christensen, J. E. Shryne, and R. A. Gorski (1977) Modifications in gonadotropin control and reproductive behavior in the female rat by hypothalamic and preoptic lesions. Brain Res. Bull. 2: 307-312.

Neill, J. D. (1972) Sexual differences in the hypothalamic regulation of prolactin secretion. Endocrinology 90: 11541159.

Nordeen, E. J., and P. Yahr (1982) Hemispheric asymmetries in the behavioral and hormonal effects of sexually differentiating mammalian brain. Science 218: 391-394.

Numan, M., J. S. Rosenblatt, and B. R. Komisaruk (1977) Medial preoptic area and onset of maternal behavior in the rat. J. Comp. Physiol. Psychol. 91: 146-164.

Olsen, K. L., and R. E. Whalen (1980) Sexual differentiation of the brain: Effects on mating behavior and $\left[{ }^{3} \mathrm{H}\right]$ estradiol binding by hypothalamic chromatin in rats. Biol. Reprod. 22: 1068-1072.

Pfaff, D. (1970) Nature of sex hormone effects on rat sex behavior: Specificity of effects and individual patterns of response. J. Comp. Physiol. Psychol. 73: 349-358.

Pfaff, D. W. (1980) Estrogens and Brain Function, SpringerVerlag, New York.

Pfaff, D. W., and Y. Sakuma (1979) Facilitation of the lordosis reflex of female rats from the ventromedial nucleus of the hypothalamus. J. Physiol. (Lond.) 288: 189-202.

Pfaff, D. W., and R. E. Zigmond (1971) Neonatal androgen effects on sexual and non-sexual behavior of adult rats tested under various hormone regimes. Neuroendocrinology 7: 129145.

Powers, B., and E. S. Valenstein (1972) Sexual receptivity: Facilitation by medial preoptic area lesions in female rats. Science 175: 1003-1005.

Wade, G. N., and I. Zucker (1970) Modulation of food intake and locomotor activity in female rats by diencephalic hormone implants. J. Comp. Physiol. Psychol. 72: 328-336.

Whalen, R. E. (1974) Sexual differentiation: models, methods, and mechanisms. In Sex Differences in Behavior, R. C. Friedman, R. M. Richart, and R. L. Vande Wiele, eds., pp. 467-481, John Wiley \& Sons, New York.

Whalen R. E., and J. Massicci (1975) Subcellular analysis of the accumulation of estrogen by the brain of male and female rats. Brain Res. 89: 255-264.

Whalen, R. E., and K. L. Olsen (1978) Chromatin binding of estradiol in the hypothalamus and cortex of male and female rats. Brain Res. 152: 121-131.

Whalen, R. E., W. G. Luttge, and B. B. Gorzalka (1971) Neonatal androgenization and the development of estrogen responsivity in male and female rats. Horm. Behav. 2: 83-90.

Winer, B. J. (1971) Statistical Principles in Experimental Design, McGraw-Hill, New York. 